\title{
ENFOQUE DE UN EVANGELISMO INTEGRAL DIDÁCTICO Y KERIGMÁTICO, PARA LA FORMACIÓN PLENA DEL DISCIPULADO EN LA MISIÓN NOR ORIENTAL DE LA IGLESIA ADVENTISTA DEL SÉPTIMO DÍA EN EL PERÚ, DURANTE EL AÑO 2012
}

Rubén Jaimes Zubieta Universidad Peruana Unión rubenjaimes@teologia.edu.pe

Rubén Montero Guerrero Universidad Peruana Unión rubenmontero@teologia.edu.pe

Juan Marcelo Zanga Céspedes Universidad Peruana Unión marcelozanga@teologia.edu.pe

Este artículo describe los resultados de la aplicación del programa piloto de evangelismo integral denominado Discipulado Total. Este programa se realizó del 8 de agosto al 6 de octubre del año 2012 en la Misión Nor Oriental, perteneciente a la Unión Peruana del Norte de la Iglesia Adventista del Séptimo Día, y contó con la participación de cincuenta y dos estudiantes de la Facultad de Teología de la Universidad Peruana Unión. Además, este estudio presenta los efectos del método de evangelismo Discipulado Total en el crecimiento de iglesia, permanencia o apostasía de los recién convertidos, y el impacto en el compromiso misionero de las iglesias que participaron en la campaña evangelística. Los resultados de esta investigación muestran que el impacto de la estrategia Discipulado Total tuvo efecto en el crecimiento de la iglesia en un 15 a 20\% más que las estrategias normales de evangelismo. Además, se constata que se ha elevado el nivel de compromiso misionero de los miembros de la iglesia, por esa razón se han mantenido el número de nuevos miembros que sobrepasan los 4400 nuevos miembros. Finalmente, se encuentra que el relacionamiento de los nuevos miembros con los antiguos es básico para la permanencia o apostasía.

Palabras clave: Evangelismo integral, discipulado, entrenamiento, desarrollo, permanencia. 


\section{FOCUSING ON DIDACTIC AND KERIGMATIC INTEGRAL EVANGELISM TO FULL DISCIPLESHIP TRAINING IN SEVENTH-DAY ADVENTIST CHURCH AT NORTH EASTERN MISSION IN PERU DURING 2012}

\section{Abstract}

This article describes the results of the implementation of the pilot program called Total Discipleship Evangelism. This program took place from August 8 to October 6 of 2012 in North Eastern Mission, which belongs to the North Peruvian Union of Seventh-day Adventist Church. For this purpose, we have fifty-two students of the Faculty of Theology of the Universidad Peruana Union. Specifically, this study shows the effects of the method of evangelism Total Discipleship in baptisms, stay or apostasy of the brand new converted, as well as the impact on the missionary commitment of the churches involved in evangelistic campaign. The results of this research shows that the impact of the strategy Total Discipleship took effect on baptisms by 15 to $20 \%$ more than normal evangelism strategies. In addition, it appears that it has raised the level of missionary commitment of the members of the church, which is why profits have remained in excess of 4400 new members. Finally, it is found that the relationship among new members with the old ones is the key to stay or apostasy.

Keywords: Integral evangelism, discipleship, training, development. 


\section{Introducción}

En los círculos eclesiásticos existen teorías variadas sobre la labor evangelística efectiva, también existen una diversidad de intentos de aplicación de esos modelos evangelísticos. Un profesor de teología aconsejaba a sus alumnos que debían leer sobre los modelos pastorales de los evangelistas más renombrados como Wesley, Horatius Bonar, Spurgeon y, entre los adventistas, el modelo pastoral "sacrificado" de Jaime White y otros pioneros del pastorado 12 adventista. Solo después de unos treinta años, de ministerio, podían crear algún nuevo modelo pastoral.

No es necesario repetir el modelo evangelístico de otros, porque solo se llegará hasta donde estos habían llegado. El pastorado también debe tener ambición, pasión, creatividad y audacia. Así que un nuevo modelo de labor pastoral enfrenta desafíos para cumplir la misión de "Id y haced discípulos... enseñándoles..” (Mt. 28:19-20). Se necesita un pastora- do que enfatice, no solo el "crecimiento numérico" sino también el "desarrollo del discipulado". La verdadera revolución misionera procederá de un pastorado innovador que aprenda a reinventar su labor misionera constantemente, de acuerdo con los desafíos del tiempo definitivo en que nos ha tocado pastorear.

\section{El evangelismo ha cambiado}

Alvin Toffler muestra cómo pasó la historia por las etapas de la era de la agricultura, la era industrial y la era de los procesos científicos. ${ }^{1}$ Ahora se vive la era del cambio y la revolución organizacional. ${ }^{2}$ Incluso, en el campo eclesiástico, Burrill indica que se habla de la "revolución en la iglesia".

La sociedad cambia constantemente, debido a la influencia de

${ }^{1}$ Alvin Toffler, El "shock" del futuro (Barcelona: Plaza \& Janes, S.A, Editores, 1970).

${ }^{2} J o s e ́$ Ignacio Porras Martínez. Cambio tecnológico y cambio organizacional. La organización en red, [en línea], 2, 2002, (consultado junio 2015). 
los medios de comunicación y el internet, por lo tanto, se hace necesario adecuar métodos evangelísticos según la necesidad social. Así, entre tanto que la mayoría de los pastores utilizan métodos de evangelismo poco efectivos, se hace necesario afrontar la época actual reevaluando los métodos y cambiarlos según cómo se los presenta en la verdad bíblica y en los consejos del espíritu de profecía, tomando en cuenta la época socio cultural vigente. Entre tanto, es preciso advertir que no se trata de innovar principios o creencias fundamentales de la fe, solo se necesita vivir la luz de la revelación ya recibida. No es necesario "innovar la fe", se trata exclusivamente de perfeccionar la metodología pastoral y misionera, frente al cumplimiento de la gran comisión de "Ir y hacer discípulos” para Jesús.

En el pastorado, la consagración sin acción no tiene frutos, se requiere con urgencia pastores audaces del mañana, que puedan innovar un modelo de pastorado misionero, e imaginar nuevos caminos y trazarse metas más ambiciosas, y conseguirlas para la gloria de Dios.

\section{El problema}

En la Iglesia Adventista del Séptimo Día (en adelante IASD) ha persistido la discusión entre los que prefieren medir la eficiencia del evangelismo por el crecimiento numérico, es decir, cantidad de miembros conversos y los que enfatizan un crecimiento espiritual de la Iglesia, es decir, la calidad espiritual de los miembros. ${ }^{3} \mathrm{Tal}$ discusión ha creado una falsa y estéril dicotomía que no toma en cuenta la visión bíblica del estilo de "evangelismo integral".

Así, aunque la Misión Nor Oriental (en adelante MNO) de la IASD es una de las regiones de mayor crecimiento numérico de miembros de Iglesia hasta el año 2012, muchos miembros de Iglesia no participan en la obra del evangelismo, pues tienen la percepción de que los programas evangelísticos solo enfatizan el crecimiento numérico (cantidad de los miembros) y no la conversión

${ }^{3}$ Russell Burrilll. Reavivamiento del discipulado: clave del éxito en la misión (Bogotá: Asociación Publicadora Interamericana, 2007). 
plena de estos (calidad espiritual de los miembros).

En tal sentido, hace falta un enfoque centrado en un estilo integral de evangelismo, que busque la plena conversión de los miembros y su pleno desarrollo mediante un programa de discipulado que priorice su perfeccionamiento y entrenamiento para el cumplimiento de su misión evangelizadora efectiva.

Así, el presente estudio desea mostrar los efectos de la implementación de un enfoque de evangelismo integral, que incluye el aspecto kerigmático (proclamación) y el aspecto didáctico (formativo) del discipulado cristiano, en la labor evangelística de la MNO de la IASD, en el Perú, durante el año 2012.

\section{Objetivo}

El objetivo principal, de esta investigación, es determinar los efectos del método de evangelismo integral en la ganancia de almas, permanencia en la Iglesia de los recién convertidos y el impacto en el compromiso misionero de las iglesias que participaron en la campaña evangelística realizada en la Misión Nor Oriental (Tarapoto, Lamas, Juanjuí, Moyobamba, Nuevo Cajamarca) de agosto a octubre de 2012.

\section{Objetivos específicos}

1. Identificar el número de bautismos como resultado del método de evangelismo integral.

2. Establecer las razones por las que los que se bautizaron, en la campaña de evangelismo integral, permanecen como miembros activos de la iglesia.

3. Determinar el nivel de compromiso misionero, de los miembros de Iglesia, como fruto de la capacitación en el marco de la campaña de evangelismo integral.

4. Identificar las razones por las que los recién convertidos abandonan la Iglesia antes de los seis meses. 


\section{Justificación}

La presente investigación permitirá verificar los resultados del método de evangelismo, denominado Discipulado Total, ayudará a aprovechar sus fortalezas y corregir sus deficiencias con miras a replicar este método en otras realidades, para el logro de un crecimiento saludable en la Iglesia.

El presente estudio puede ayudar a solucionar el paradigma de medir el evangelismo solo en términos de cantidad porque, en su generalidad, se tiene la tendencia de definir el evangelismo en términos de números, de probabilidades y de estadísticas, en vez de hacerlo desde una perspectiva más integral. ${ }^{4}$

\section{Dimensión didáctica del evangelismo}

La dimensión didáctica, en el cumplimiento de la misión, está

${ }^{4}$ J. I. Packer, El evangelismo y la soberanía de Dios, trad. Glenn A. Martínez (Graham, NC: Publicaciones Faro de Gracia, 2008), 39. referida a la centralidad de la enseñanza en el proceso del discipulado. El énfasis de las actividades evangélicas, para el cumplimiento de la misión, debe estar en la enseñanza por medio del discipulado. La Gran Comisión de Cristo, dada a su Iglesia, se resumió en el mandato de "haced discípulos a todas las naciones" (Mat. 28:19). Estas palabras indican que los discípulos tenían que salir al mundo para ganar a otros que llegarían a ser lo que ellos mismos eran: discípulos de Cristo. ${ }^{5}$

Elena de White declara:

En el mandato, dirigido a sus discípulos, Cristo no solo esbozó su obra, sino que les dio su mensaje. Enseñad al pueblo, dijo, "que guarden todas las cosas que os he mandado". Los discípulos habían de enseñar lo que Cristo había enseñado, y eso incluye lo que él había dicho, no solamente en persona, sino por todos los profetas y maestros del Antiguo Testamento. ${ }^{6}$

${ }^{5}$ Robert Coleman, Plan supremo de evangelización, trad. José María Blanch (El Paso, TX: Casa Bautista de Publicaciones, 2004), 90.

${ }^{6}$ Elena G. de White. El evangelismo (Buenos Aires: Asociación Casa Editora Sudamericana, 1975), 15. 
Además, añade:

"La obra evangélica, la tarea de abrir las Escrituras a otros, el amonestar a hombres y mujeres acerca de lo que sobrevendrá al mundo, ha de ocupar más y más el tiempo de los siervos de Dios. ${ }^{?}$

La actividad de enseñanza, dentro del contexto de evangelismo, tiene resultados amplios para el desarrollo individual en el campo espiritual, de ello depende el desarrollo personal. Guy P. Duffield y Nathaniel M. Van Cleave afirman que "la predicación es el ministerio de reclutamiento y motivación de la Iglesia; la enseñanza es el ministerio que produce la madurez. Mediante la predicación, nacen nuevos bebés en la familia de Dios; mediante la enseñanza, los bebés son madurados de la leche a la carne fuerte". 8

El pastor tiene como tarea capacitar a los miembros de la Iglesia en el trabajo misionero. Sobre el particular, Elena de White de-

${ }^{7}$ Ibíd., 16.

${ }^{8}$ Guy P. Duffield y Nathaniel M. Van Cleave, Fundamentos de teologia pentecostal (San Dimas, CA: Foursquare Media, 2006), 467. clara: "Tan pronto como se organice una iglesia, ponga el ministro a los miembros a trabajar. Necesitarán que se les enseñe cómo trabajar con éxito". ${ }^{9}$ Su tarea es entrenar en “...El evangelismo persona a persona requiere que haya comunicación a través del estilo de vida, por la palabra y por los hechos. ${ }^{10}$ El entrenamiento, en evangelismo personal, es mejor cuando se hace a través de situaciones reales. Y es particularmente eficaz si el entrenador puede enseñar y observar al discípulo por un período de tiempo razonable. ${ }^{11}$

Un aspecto importante, de la capacitación a la Iglesia, debe ser en el arte de dar estudios bíblicos. Elena de White dice: "El plan de celebrar estudios bíblicos es una idea de origen celestial. Muchos son los hombres y mujeres que pueden dedicarse a este ramo del trabajo misionero. Pueden desa-

${ }^{9}$ White, Evangelismo, 260.

${ }^{10} \mathrm{Jim}$ Chew, La otra ocupación, Trabajando tu llamado a las naciones: Una guía para el misionero biocupacional, ed. Jonatán P. Lewis (Miami, FL: Editorial Unilit, 1995), 125.

${ }^{11}$ Ibid. 
rrollarse, así, obreros que serán poderosos para Dios... La Biblia penetra en las familias, y sus verdades sagradas penetran en la conciencia. Se ruega a los hombres que lean, examinen y juzguen por sí mismos, y deben llevar la responsabilidad de recibir o rechazar la ilustración divina". ${ }^{2}$ Visitad a las familias, orad por ellas, conversad con ellas, escudriñad las Escrituras con ellas, y les haréis bien. Dadles evidencia de que buscáis su prosperidad y que queréis que sus miembros sean cristianos sanos. $^{13}$

\section{Dimensión kerigmática del evangelismo}

La dimensión kerigmática, del evangelismo, está referida a la proclamación del mensaje de Cristo. Esta proclamación incluye el testimonio personal, el evangelismo personal y la predicación pública. La diferencia entre el testimonio personal y el evangelismo perso-

${ }^{12}$ Elena G. de White. Obreros evangélicos, (Buenos Aires: Asociación Casa Editora Sudamericana, 1957), 200.

${ }^{13}$ Idíd., 256. nal es que el testimonio no necesita ser hablado, pues es la predicación a través de la vida cristiana del creyente.

Esta dimensión kerigmática implica la búsqueda intencional de aquellos que todavía no han entregado sus vidas a Jesús, y no están viviendo de acuerdo con los preceptos divinos. Esta actividad no es prerrogativa únicamente de los dirigentes de la Iglesia o quienes ocupan cargos de responsabilidad. No todos tendrán la oportunidad de predicar frente a grandes auditorios, ni la de administrar estudios bíblicos con eficiencia, pero todos son llamados a testificar. Se hace necesario enseñar y motivar a los miembros de la Iglesia a involucrarse en el evangelismo personal para que su liderazgo espiritual se desarrolle. Stockstill afirma que "el primer nivel, en el que un líder potencial debe ser entrenado, es en la habilidad de 'predicar el evangelio a cada persona'. El evangelismo sencillo brota de un deseo de ganar almas.

Si la persona no vence la timidez, en cuanto al evangelismo 
personal, nunca entrará en el liderazgo espiritual". ${ }^{14}$ Por su parte, Torrey dice que el métodos más eficaz es el personal porque 1 . Todos pueden hacerlo; 2. En todo lugar; 3. En todo tiempo; 4. A todo rango; 5. Da en el blanco y 6. Satisface. ${ }^{15}$

Para tener éxito en el evangelismo, es necesario seguir el método del mayor evangelista de la historia: Jesucristo. El método de Cristo, para realizar evangelismo, no era solamente el mensaje delante de las grandes multitudes, sino se concentraba en el trabajo individual. Elena de White declara: "El Salvador se mezclaba con los hombres como alguien que deseaba su bien. Les manifestaba simpatía, atendía sus necesidades y ganaba su confianza. Luego los invitaba así: "Sígueme" ${ }^{16}$ En realidad el esfuerzo evangelístico más

${ }^{14}$ Stockstill, La iglesia celular, 88. Citado por (Pablo A. Deiros, La Iglesia Celular, Formación Ministerial (Buenos Aires: Publicaciones Proforme, 2011), 165-6.

${ }^{15}$ Daniel Campderros, Bosquejos bíblicos: Tomo II (El Paso, TX: Casa Bautista de Publicaciones, 2003), 80.

${ }^{16}$ White, Obreros evangélicos, 376. eficaz es el que reconoce el esfuerzo personal por ayudar a los necesitados. Ella añade: "Es necesario acercarse a la gente por el esfuerzo personal. Si se dedicase menos tiempo a sermonear, y más al ministerio personal, se verían mayores resultados. Hay que aliviar a los pobres, cuidar a los enfermos, consolar a los tristes y afligidos por el duelo, instruir a los ignorantes, aconsejar a los inexpertos. Hemos de llorar con los que 1loran, y regocijarnos con los que se regocijan. Acompañada del poder de la persuasión, del poder de la oración, del poder del amor de Dios, esta obra no podrá quedar sin fruto. ${ }^{17}$

El contexto evangelístico actual requiere de una práctica que demuestre convicción, es decir debe existir una relación entre lo que proclamamos y lo que predicamos. "Si usted está presentando la Palabra, según el método de Cristo, su auditorio quedará profundamente impresionado, con las verdades que enseña. A ellos les llegará la convicción, de que esta

\footnotetext{
${ }^{17}$ Ibid., 376.
} 
es la palabra Dios". ${ }^{18}$ En su enseñanza había un fervor que hacía penetrar sus palabras en el corazón con poder convincente. ${ }^{19}$ Pero aunque su enseñanza era sencilla, hablaba como persona investida de autoridad. Esta característica ponía su enseñanza en contraste con la de los demás. Los rabinos hablaban con dudas y vacilación, como si se pudiese entender que las Escrituras tenían un significado u otro, exactamente opuesto. Los oyentes estaban diariamente envueltos en mayor incertidumbre. Pero al enseñar, Jesús presentaba las Escrituras con autoridad indudable. Cualquiera que fuese el tema, lo exponía con poder, con palabras incontrovertibles. ${ }^{20}$

Los pastores estamos llamados a practicar y enseñar el trabajo evangelístico personal y de éxito que practicó Jesús. "El plan de Jesús no ha sido repudiado, se ha

${ }^{18}$ Elena G. de White. La voz, su educación y su uso correcto, (Buenos Aires: Asociación Casa Editora Sudamericana, 2002), 57

${ }^{19}$ White. El Evangelismo, 356.

${ }^{20}$ Elena G. de White. El deseado de todas las gentes (Buenos Aires: Asociación Casa Editora Sudamericana, 1955), 218. prescindido de él. Se ha convertido en algo digno de recordar, perteneciente al pasado, pero no se ha tomado en serio como norma de conducta para el presente". ${ }^{21}$

Existe una diferencia real en lo que se pretende en evangelismo, algunos direccionados a las ceremonias y otros a buscar métodos, sin embargo, se necesita equilibrio en la práctica. Este es el problema metodológico actual. Ceremonias, programas, organizaciones, comisiones y cruzadas, todo bien intencionado y fruto del ingenio humano, se ponen a prueba con generosidad para que cumplan una labor que solo pueden realizar hombres movidos por el poder del Espíritu Santo. Esto no es tener en menos tales esfuerzos, porque sin ellos la Iglesia no podría funcionar como lo hace. Sin embargo, a no ser que la misión personal del Maestro se incorpore vitalmente al plan de acción y a la entraña misma de todas estas iniciativas, la Iglesia no podrá funcionar como debería hacerlo. ${ }^{22}$

${ }^{21}$ Coleman, 93.

${ }^{22}$ Coleman, 93. 
Esta es la evangelización nueva que necesitamos. No es métodos mejores sino hombres mejores-hombres que conozcan a su Redentor por algo más que de oídas-hombres que tengan su visión y sientan su pasión por el mundo-hombres que estén dispuestos a no ser nada para que él lo sea todo-hombres que solo quieran que Cristo reproduzca su vida en ellos y por medio de ellos, según su voluntad. Este es, en último término, el camino que el Maestro ideó para que se realice su objetivo en la tierra y donde se aplica, con su estrategia, que las puertas del infierno no pueden prevalecer contra la evangelización del mundo. ${ }^{23}$

\section{Evangelismo y discipulado}

El verbo principal, en la comisión evangélica dada por Jesús, es el mandato a "hacer discípulos". Discipular a una persona hacia Cristo es traerlo a una relación de alumno a maestro. Los discípulos

23Íbid.,, 94. son los que escuchan, entienden y obedecen las enseñanzas de Jesús (12:46-50). La orden se le da, por lo menos, a los once en su papel de discípulos (v. 16). Por lo tanto, son modelos para todos los discípulos. En otras palabras, el cumplimiento de la Gran Comisión es el deber de todos los creyentes.

Discipular a nuevos creyentes es el paso que sigue al evangelismo. La meta es ver al nuevo cristiano crecer y madurar en su propia cultura y que se convierta en un testigo efectivo en medio de su familia y su comunidad. ${ }^{24}$

Adviértase que no es suficiente rescatar a alguien para que no perezca, aunque es obligatorio hacerlo; ni tampoco es suficiente instruir a los recién nacidos en la fe en Cristo, aunque también esto es necesario si se quiere que el primer fruto perdure; de hecho, no es suficiente conseguir que salgan a ganar almas, por encomiable que dicha labor sea. Lo que en realidad vale, en la continuidad final de nuestra obra, es la fidelidad con la que nuestros conversos

${ }^{24}$ Chew, 131. 
salen a formar líderes de sus conversos, y no simplemente seguidores. $^{25}$

Pero, ¿qué se quiere decir precisamente con "haced discípulos"? No es exactamente lo mismo que "haced convertidos"; aunque, por supuesto, lo segundo queda implícito. El término "haced discípulos" pone algo más de énfasis en el hecho de que tanto la mente como el corazón y la voluntad deben ser ganadas para Dios. Un discípulo es un alumno, un aprendiz. $^{26}$

Los discípulos, antes de llegar a ser apóstoles, tuvieron que desarrollarse en la etapa del discipulado. Entonces ellos pudieron proclamar la verdad y la voluntad de Dios al mundo. Es necesario que los pecadores sepan acerca de su propia condición perdida, del amor de Dios, de su plan de redención, de su ley, etc. Sin embargo, esto no es suficiente. El verdadero discipulado implica

${ }^{25}$ Coleman, 91.

${ }^{26}$ William Hendriksen, Comentario al nuevo testamento: El evangelio según San Mateo (Grand Rapids, MI: Libros Desafío, 2007), 1048. mucho más. Un entendimiento puramente mental, hasta ahora, no ha hecho ningún discípulo. Es parte del cuadro, de hecho una parte importante, pero solo una parte. La verdad aprendida debe ser practicada. Debe ser asimilada por el corazón, la mente y la voluntad, para que uno permanezca o continúe en la verdad. Solo entonces uno es verdaderamente "discípulo" de Cristo (Jn. 8:31). ${ }^{27}$

Los conceptos "bautizar" y "enseñar" son simplemente dos actividades, coordinadas la una con la otra, pero ambas subordinadas a "hacer discípulos". En otras palabras, por medio de ser bautizada e instruida una persona llega a ser un discípulo, en el entendido, por supuesto, de que este individuo está preparado para el bautismo y dispuesto a apropiarse de la enseñanza. El contexto deja muy claro que Jesús aquí está hablando de aquellos que son lo suficientemente maduros para ser considerados objetos de la predicación. Aquí él no está hablando de niños pequeños. ${ }^{28}$

${ }^{27}$ Hendriksen, 1048

${ }^{28}$ Ibíd., 1049. 
Esta misión se ve todavía con mayor claridad cuando se estudia el texto griego, y se ve que los verbos “ir", "bautizar", y "enseñar” están todos en participio, y estos participios derivan su fuerza del verbo principal "hacer discípulos". Esto significa que la gran comisión no es simplemente ir hasta los confines de la tierra predicando el evangelio (Mar. 16:15), ni bautizar a muchos convertidos en el nombre del Dios Trino, ni enseñarles los preceptos de Cristo, sino "hacer discípulos": preparar a hombres como ellos, que se sintieran tan constreñidos por la comisión de Cristo que no solo siguieran, sino guiaran a otros para que siguieran el camino. Solo cuando se hicieran discípulos podrían cumplir su propósito las otras actividades de la comisión. ${ }^{29}$

\section{Evangelismo Discipulado Total en Tarapoto}

\section{Definición y alcances}

El programa de evangelismo DISCIPULADO TOTAL, con el

\footnotetext{
${ }^{29}$ Coleman, 90.
}

lema viva con esperanza, fue llevado a cabo en la Misión Nor Oriental del Perú de la Iglesia Adventista del Séptimo Día, con sede en la ciudad de Tarapoto, en el año 2012, con el apoyo de cincuenta y dos estudiantes del octavo ciclo quienes cursan el cuarto año de la Facultad de Teología, de la Universidad Peruana Unión.

\section{Objetivos}

El objetivo general de este modelo de evangelismo fue lograr el desarrollo integral, entrenamiento y movilización misionera de 10,000 miembros de Iglesia para alcanzar su madurez como discípulos de Jesús y con su participación misionera bautizar, al menos, 2000 nuevos discípulos, integrándolos a los Grupos Pequeños de la IASD en la Misión Nor Oriental del Perú.

Los objetivos específicos del uso de estas estrategias para el desarrollo espiritual de la membresía, y para el desarrollo de las actividades misioneras, fueron:

1. Lograr el reavivamiento integral de la Iglesia, me- 
diante la comunión diaria (personal y familiar) con Cristo.

2. Lograr la fidelidad plena de la Iglesia en la Mayordomía integral.

3. Lograr el entrenamiento y el compromiso misionero vital del discipulado, para terminar la obra de Dios en esta generación.

4. Lograr el fortalecimiento pleno de los grupos pequeños.

5. Lograr el entrenamiento de 800 pastores voluntarios y 1200 parejas misioneras, para involucrarlos en la campaña VIVA CON ESPERANZA.

6. Lograr la enseñanza del modelo bíblico de labor pastoral entrenador (no clerical), consistente en: 1 ) el "perfeccionamiento de los santos", para que estos cumplan su ministerio en la edificación de la Iglesia (Efe 4:11,12); 2) la creencia del "sacerdocio [pastorado] universal de todos los creyentes" (2 Pedro 2:9); 3 ) y el llamado a la obra del "pastorado voluntario" de todos los discípulos de Jesús (1 Pedro 5:1-4).

7. Lograr 2000 bautismos de nuevos discípulos e iniciar su desarrollo integral en el programa del Ciclo de Discipulado, en cuanto a su compromiso misionero y la preparación de la Iglesia para su encuentro con Jesús.

\section{Estrategia}

La estrategia del programa fue elaborada teniendo en cuenta dos frentes: La estrategia interna, que fue denominada VIVA CON ESPERANZA sirviendo para la movilización de los miembros de la Iglesia y su participación en la campaña de evangelismo. Las estrategias externas consistieron en la promoción de UN ESTILO DE VIDA SALUDABLE y la promoción del HÁBITO DE LECTU. RA (usando los libros misioneros de la IASD), en contacto con las organizaciones barriales e instituciones de la sociedad, así como sus 
líderes y autoridades correspondientes, en especial el de las instituciones educativas convocando a los alumnos para la promoción del hábito de lectura y a los padres de familia, a las escuelas para padres y otros conferencias para el desarrollo de la niñez, la juventud y la sociedad en general.

Antes, y con la llegada de los estudiantes, los grupos pequeños y las parejas misioneras, recibieron el entrenamiento y la motivación adecuada para realizar una campaña agresiva de siembra, cultivo y primeras cosechas en grupos pequeños. A partir de allí se realizó un ajuste en la organización y fase intensiva de la campaña por 30 días, mediante:

1. El trabajo del profesor-entrenador de Evangelismo de la UPeU.

2. El trabajo de 52 estudiantes entrenadores del pastorado voluntario (miembros de la Iglesia comprometidos para el trabajo misionero).

3. El trabajo de 800 pastores voluntarios o líderes de grupos pequeños, supervisados mediante la estrategia del calendario.

4. El trabajo de estudios bíblicos de 1200 parejas misioneras.

5. Y el trabajo misionero de 2400 discípulos misioneros. Todos inscritos en el "Libro de Oro" para el historial de la campaña.

La última parte de la estrategia tomaba en cuenta 30 días finales, durante los cuales se realizaron campañas evangelísticas en tres niveles, con los Grupos Pequeños, hasta la gran cosecha que se realizó a fines de setiembre del año 2012, con la caravana evangelística VIVA CON ESPERANZA y con la participación de estudiantes como dos evangelistas que recorrieron dos rutas principales: la ruta de Tarapoto a Juanjui y la ruta de Tarapoto a Nueva Cajamarca. La idea era que los estudiantes no hagan el trabajo de evangelismo solos como los "profesionales", dejando a los hermanos como espectadores, sino que actuaron como entrenadores 
para el desarrollo de los discípulos.

Los resultados finales de la campaña fueron: el reavivamiento misionero de la iglesia, el desarrollo integral de los discípulos y las 2511 almas bautizadas.

\section{Resultados}

A continuación, presentamos los resultados de la investigación sobre el programa de evangelismo Discipulado Total, distribuidos en el crecimiento en el número de bautismos, las razones de permanencia en la Iglesia, el compromiso misionero de los nuevos miembros y las principales razones que esgrimen aquellos que abandonaron la Iglesia.

\section{El crecimiento en el número de bautismos}

1. Se ha identificado un crecimiento superior al $40 \%$ en número de bautismos entre los meses de agosto y octubre, este número superior al normal es resultado directo del uso del método evangelismo integral.

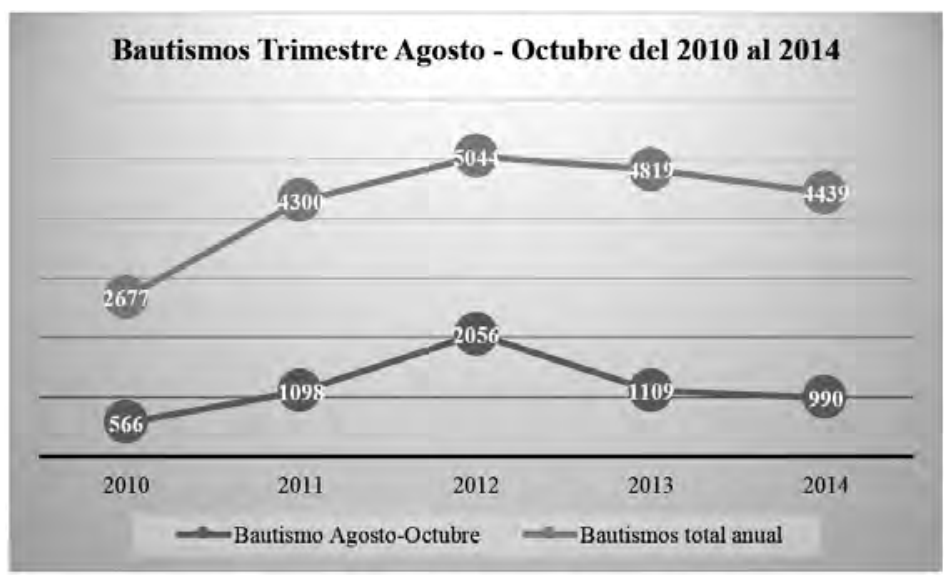

Figura 1: Comparación de bautismos entre los años 2010 y 2014 en el período agosto - octubre, en relación al bautismo total de cada año. 
2. El crecimiento, en número de miembros recién bautizados, durante los meses de agosto, setiembre y octubre, se elevó el 2012, comparado con los mismos meses de los años 2010, 2011, 2013 y 2014. El aporte trimestral al total anual de nuevos miembros de la Iglesia entre agosto y octubre de los años 2010, 2011, 2013 y 2014 varía entre el 21 y $25 \%$. Sin embargo, con el uso de la estrategia de evangelismo integral se
4. Se concluye que el aporte de la estrategia de evangelismo integral ha tenido éxito en la proclamación del evangelio, porque ha aumentado entre un 15 a $20 \%$ más a la tendencia normal de crecimiento de la Iglesia adventista en Tarapoto.

\section{Razones de permanencia en la iglesia}

En relación con las razones que esgrimen los bautizados en la campaña Discipulado Total para permanecer en la Iglesia, los resultados obtenidos se muestran en la tabla 1:

3. Como repercusión posterior, a la época de la campaña, se añadieron más de 400 nuevos miembros entre los meses de noviembre y diciembre del 2012. 
Tabla 1: Razones de permanencia de miembros bautizados entre Agosto-Octubre 2012

\begin{tabular}{|c|l|c|c|}
\hline Nro & \multicolumn{1}{|c|}{ Razones de permanencia } & Frecuencia & Porcentaje \\
\hline 1 & La observancia del sábado & 101 & 50.8 \\
\hline 2 & Compañerismo entre los miembros & 92 & 46.2 \\
\hline 3 & Participación en la iglesia & 92 & 46.2 \\
\hline 4 & Apoyo de familiares Adventistas & 91 & 45.7 \\
\hline 5 & Participación en los grupos pequeños & 88 & 44.2 \\
\hline 6 & Devoción personal & 85 & 42.7 \\
\hline 7 & Conocimiento de doctrinas & 81 & 40.7 \\
\hline 8 & Adaptación al estilo de vida adventista & 80 & 40.2 \\
\hline 9 & Cultos y adoración inspiradores & 80 & 40.2 \\
\hline 10 & Apoyo de los dirigentes & 74 & 37.2 \\
\hline 11 & Visitación de otros hermanos & 70 & 35.2 \\
\hline 12 & Trabajo misionero & 60 & 30.2 \\
\hline 13 & Buena preparación para el bautismo & 59 & 29.6 \\
\hline 14 & Visitación pastoral & 49 & 24.6 \\
\hline 15 & Clases posbautismales & 33 & 16.6 \\
\hline
\end{tabular}

Fuente: Elaboración propia basado en la encuesta realizada en Julio 2013.

Como se puede observar, las primeras seis razones para que los bautizados, entre agosto y octubre del 2012, permanezcan en la Iglesia son: primero, la observancia del sábado con un $50.8 \%$; segundo, el compañerismo entre los miembros y la participación en la iglesia comparten el 46.2\%; tercero, el apoyo de familiares adventistas con un 45.7\%; en cuarto lugar, la participación en los grupos pequeños con un $44.2 \%$; y, en el quinto lugar, se ubica la devoción personal con el $42.7 \%$. Entre tanto, los elementos que menos han contribuido a la permanencia de los nuevos conversos han sido: la visitación de otros hermanos, el trabajo misionero, la buena preparación para el bautismo, la visitación pastoral y las clases bautismales que oscilan entre el 35 y $16 \%$. 
Si se toma en cuenta estos datos, se puede deducir que el relacionamiento con los miembros de la iglesia, los días sábados con la familia y los grupos pequeños, tiene relación con la permanencia de los recién bautizados. Estos resultados se explican debido a que los nuevos convertidos salen de un medio social a otro, por lo tanto, buscan nuevas formas de relacionamiento, priorizando la búsqueda de amistades de la iglesia y de la familia que apoya o incentiva el cristianismo o la práctica de la religión.

Se concluye que las actividades de relacionamiento, de los nuevos conversos con los miembros de iglesia y con sus familiares quienes comparten la misma fe, son las que más ayudan en la permanencia de los nuevos conversos.

\section{El compromiso misionero de la iglesia}

El impacto en el compromiso misionero de la hermandad de la Misión Nor Oriental ha sido duradero. Es necesario enfatizar que el trabajo misionero se mide por la cantidad de personas llevadas a los pies de Cristo, por lo tanto, la demostración visible de entrega y conversión son el bautismo, por lo menos primariamente, así que con ese entendido se puede indicar que, a partir del 2012, la cantidad de bautismos alcanzados por el campo misionero no ha bajado de 4400 , más bien ha aumentado.

Si se hace una análisis más profundo, se puede encontrar que el año 2010, en el mismo territorio, se llegó a 2677 nuevos bautizados, el año 2011 se alcanzó a 4300, pero a partir del 2012, cuando se implementó la estrategia de evangelismo integral en el que se destaca la predicación y el discipulado, llegó a 5044 y, a partir de ese años, debido a la capacitación en el área misionera, creemos que ha afectado para que la cantidad de nuevos miembros de iglesia crezca para los años 2013 llegando a 4819 y el 2014 llegando a 4439.

Se concluye que la implementación de evangelismo integral de predicación y, sobre todo, la capacitación en el trabajo misionero, ha motivado la actividad misio- 
nera posterior de los miembros de iglesia que participaron en la campaña, por esa razón entre los años 2013 y 2014 continuaron con tendencias elevadas, en cuanto a número de nuevos miembros de iglesia.

\section{Razones por qué abandonan la iglesia}

Se ha identificado algunas de las razones por las cuales los nuevos convertidos abandonan la Iglesia, antes de cumplir los 12 meses.

Tabla 2. Razones de apostasía de miembros bautizados entre Agosto-Octubre 2012

\begin{tabular}{|c|l|c|c|}
\hline Nro & \multicolumn{1}{|c|}{ Razones para apostasía } & Frecuencia & Porcentaje \\
\hline 1 & Poco conocimiento de las doctrinas & 18 & 25.4 \\
\hline 2 & Problemas personales & 16 & 22.5 \\
\hline 3 & Desánimo y abatimiento & 12 & 16.9 \\
\hline 4 & Ausencia y no participación en los grupos pequeños & 12 & 16.9 \\
\hline 5 & Falta de compañerismo entre los miembros & 10 & 14.1 \\
\hline 6 & Indiferencia hacia los nuevos conversos & 8 & 11.3 \\
\hline 7 & Preparación deficiente para el bautismo & 8 & 11.3 \\
\hline 8 & Oposición de familiares no adventistas & 8 & 11.3 \\
\hline 9 & Cultos y adoración deficientes & 8 & 11.3 \\
\hline 10 & Caí en pecado & 7 & 9.9 \\
\hline 11 & Problemas con los miembros antiguos & 6 & 8.5 \\
\hline 12 & Poca participación misionera & 6 & 8.5 \\
\hline 13 & Deficiente atención posbautismal & 6 & 8.5 \\
\hline 14 & Pocas oportunidades de participación en la iglesia & 6 & 8.5 \\
\hline 15 & Problemas con los dirigentes & 5 & 7.0 \\
\hline 16 & Problemas para adaptarse al estilo de vida adventista & 5 & 7.0 \\
\hline 17 & Desacuerdo con las doctrinas & 3 & 4.2 \\
\hline 18 & Injusticias dentro de la iglesia & 3 & 4.2 \\
\hline 19 & La observancia del sábado & 3 & 4.2 \\
\hline
\end{tabular}

Fuente: Elaboración propia basado en la encuesta realizada en Julio 2013. 
Entre las primeras cinco razones del por qué los que apostatan lo hacen, figura: En primer lugar, el poco conocimiento de las doctrinas con un $25.4 \%$, en segundo lugar, los problemas personales con el $22.5 \%$, en tercer lugar, se comparte el desánimo y abatimiento y la ausencia y no participación en grupos pequeños con un $16.9 \%$; en cuarto lugar, la falta de compañerismo entre los miembros con un $14.1 \%$ y en quinto lugar compartido por indiferencia hacia los nuevos conversos, preparación deficiente para el bautismo, oposición de familiares no adventistas, cultos y adoración deficientes con un $11.3 \%$, respectivamente.

Si se hace un análisis de estos datos, se puede indicar que la principales razones de apostasía tienen que ver con el conocimiento doctrinal y el relacionamiento. En el caso de relacionamiento, los nuevos conversos necesitan de una esfera social donde puedan compartir sus aspiraciones, sus problemas sus triunfos y sus abatimientos. Como los nuevos conversos, posiblemente vengan de un entorno social con un estilo de vida diferente y no tienen una interrelación personal con los miembros de la iglesia, tampoco asisten a los grupos pequeños donde se atiende necesidades espirituales y de interrelación, además no llegan a establecer relaciones significativas con los demás miembros de la iglesia por lo que se abaten, se frustran y, finalmente, dejan la Iglesia.

Se concluye que la falta de relacionamiento, con los miembros de la iglesia los sábados, con los miembros de los grupos pequeños y con familiares que profesan la misma religión o tienen familiares de diferente línea religiosa son las principales razones para la apostasía.

\section{Conclusiones}

1. Se ha identificado un crecimiento superior al 40 $\%$, aumentando en más de 15 a $20 \%$ la tendencia normal en número de bautismos entre los meses de agosto a octubre, de los 
años 2010, 2011, 2013 y

2014. Este número superior al normal es resultado directo del uso del método evangelismo integral del 2012.

2. Se identificó que las razones de relacionamiento, de los recién bautizados en la campaña de evangelismo integral, son las más importantes para que ellos permanezcan como miembros activos de la iglesia, porque indican que el compañerismo entre los miembros y la participación en la iglesia, el apoyo de familiares adventistas y la participación en los grupos pequeños son actividades ubicados, por ellos, entre las primeras cinco razones.

3. Se determinó que el nivel de compromiso misionero, de los miembros de la Iglesia Adventista del Séptimo Día de la Misión Nor Oriental, se ha ele- vado. Porque como fruto del trabajo misionero de los miembros de iglesia, la cantidad de bautismos no ha bajado de 4400 desde la campaña de evangelismo integral.

4. Se identificó que la falta de relacionamiento con los miembros de la iglesia durante los cultos de sábados, la falta de participación o asistencia a los grupos pequeños, la falta de relacionamiento con ellos y la influencia de familiares que no profesan la misma religión, son las principales razones para la apostasía de los nuevos miembros. 